\title{
To identify the seed borne mycoflora associated with pigeonpea seeds by Standard Blotter Method
}

\author{
S.N. Sharma
}

Department of Plant Pathology, N.P.G. College, Barhalganj, Gorakhpur (U.P.) India

\section{ARITCLE INFO \\ Received : 06.06 .2019 \\ Revised : 27.08 .2019 \\ Accepted : 13.09.2019}

\section{KEY WORDS :}

Pigeonpea, Mycoflora, Seed born fungi

*Corresponding author:

Email : drsnsharam4@gmail.com

\begin{abstract}
The study aims at identifying seed borne fungi associated with Cajanus cajan L. Mill sp. Nineteen varieties of pigeanpea were collected from various places in different agroclimatic zones for the detection of seed mycoflora associated with them. The seed born fungi was screened by using Standard blotter plate method from selected untreated and treated seeds. A total of 14 fungal species were found associated with pigeonpea seeds of different varieties with varying degree of incidence in standard blotter method (Untreated ). The detected fungi were Fusarium monillifoarmae, Alternaria alternate, Aspergilus flavus, Aspergilus niger, Aspergilus fumigates, Aspergilus candidus, Cladosporium cladosporoides, Curvularia lunata, Rhizoctonia solani, Drechsera tetramera, Penicillium oxalicum, Mucor spp., Rhizopus nigricans and Cheatomium globosum. The maxium number of fungal species were associated with seeds of variety UPAS-120 .In this method (Pre-treated) 11 fungal species were detected. The Treatment reduced the average number of colonies of each fungus associated with seeds of different varieties considerably while 4 fungal species such as Penicillium oxalicum, Mucor spp. Rhizopus nigricans and Chaetomium globosum.
\end{abstract}

How to view point the article : Sharma, S.N. (2019). To identify the seed borne mycoflora associated with pigeonpea seeds by Standard Blotter Method. Internat. J. Plant Protec., 12(2) : 123-126, DOI : 10.15740/HAS/IJPP/12.2/123-126, Copyright@ 2019: Hind Agri-Horticultural Society. 